\title{
Stabilizing O/W Emulsions by Soy Protein Concentrate + Maltodextrin and Optimizing the Process by Using Response Surface Methodology
}

\author{
Azadeh Salimi ${ }^{1, *}$, Yahya Maghsoudlou², Seyyed Mahdi Jafari², Alireza Sadeghi Mahounak², \\ Mahdi Kashani nejad ${ }^{2}$, Aman Mohammad Ziaiifar ${ }^{2}$ \\ ${ }^{1}$ Veterinary Department, Semanan University, Semann, Iran \\ ${ }^{2}$ Food Science and Technology Department, Agricultural Sciences and National Resources University of Gorgan, Gorgan, Iran
}

Copyright $(2017$ by authors, all rights reserved. Authors agree that this article remains permanently open access under the terms of the Creative Commons Attribution License 4.0 International License

\begin{abstract}
Stability is one of the key quality parameters of emulsion systems, which goes a long way in predicting the shelf life of emulsion products. In this study, the effect of emulsifier (soy protein concentrate (SPC) + maltodextrin (MDX)), dispersed phase (lycopene in oil solution) and homogenizer speed on emulsion stability were investigated and optimized using response surface methodology (RSM). Independent variables were lycopene content $(10-20 \%$, w/w), SPC+ MDX as emulsifier and surfactant (30-40\%, w/w) and the homogenizer speed (14000-18000 rpm). Responses were droplet size, viscosity and creaming index as stability indicators of the emulsions. According to RSM analysis and models, optimized variables showed a good fit to quadratic equations for droplet size and viscosity with correlation coefficients $\left(\mathrm{R}^{2}\right)$ of 0.9571 and 0.9826 , respectively. After model simplification with backward stepwise solution, the $\mathrm{R}^{2}$ values for droplet size and viscosity decreased slightly to 0.9504 and 0.9826 , respectively. Creaming values were fitted properly with linear model, and $\mathrm{R}^{2}$ was 0.8030 . Graphical optimization methods were adapted for preparing the best lycopene emulsifying conditions and were predicted to be: homogenizer speed of $18000 \mathrm{rpm}$; lycopene content of 20\% $\mathrm{w} / \mathrm{w}$, and SPC+MDX concentration of $36.95 \% \mathrm{w} / \mathrm{w}$.
\end{abstract}

Keywords Emulsion, Soy Protein Concentrate, Maltodextrin, Optimization, Response Surface Methodology

\section{Introduction}

Oil-in-water emulsions are systems that are composed of two immiscible liquids such as oil and water [1]. They consist of small spherical oil droplets in an immiscible aqueous phase [2]. Generally, emulsions are thermodynamically unstable systems due to an increase in interfacial area following emulsification. Hence, after enough time, they collapse, into parent phases in order to minimize the contact area [3]. It is possible to form a kinetically stable (metastable) emulsion for a reasonable period of time by reducing their destabilization rate to adequately low level [4] by adding emulsifiers and/or thickening agents prior to homogenization [2]. In order to increase the activation energy of the system [5], some other variables, such as Proteins are usually employed in $\mathrm{O} / \mathrm{W}$ emulsions due to their ability to reduce interfacial tension between oil and water, and to form films that act as a physical barrier, as well as prevent flocculation and coalescence of droplets [6]. In particular, soy protein is a good alternative due to its high nutritional value and low cost than other sources of proteins. Emulsifying and foaming properties are important properties of soy protein concentrates (SPC), and are useful in stabilizing emulsion systems.

Polysaccharides are another group of biopolymers which can be used as stabilizers mainly because of their hydrophobicity, highly-branched structure, high molecular weight, thickening ability and gelling characteristics. They form macromolecular barriers against destabilizing mechanisms by increasing the continuous phase viscosity [7]. Polysaccharides, such as gums and MDX, can be used in combination with other biopolymers, such as whey proteins, to optimize their emulsification and film forming properties [8].

Droplet size is one of the most important parameters that influences emulsion stability, and is affected by homogenization method, quantity of dispersed and continuous phases, as well as viscosity of the two phases. 
Lower droplet size can be achieved by using increasing pressure, shear rate and energy density, which leads to more stability in emulsions $[9,10,11]$. Also, it is important to improve the performance of the systems and to increase the yield of the processes without increasing the cost. The method used for this purpose is called optimization. RSM is a collection of statistical and mathematical techniques useful for developing, improving and optimizing processes, in which a response of interest influenced by several variables is optimized [12, 13].

The objective of this study was to develop an RSM-based optimization technique for improving lycopene emulsion stability by natural biopolymers (SPC+MDX) and to obtain optimum operating conditions for further processing.

\section{Materials and Methods}

\subsection{Materials}

Lycopene was purchased from Anhui Minmetals Development Company (Anhuai, China). Maltodextrin (DE20) and SPC 80\% were produced from Qinhuangdao Lihua Starch Co. Ltd (Qinhuangdao, China), and Wachsen Company (Shandung, China), respectively. Soy oil was purchased from Salimi Industrials (Tabriz, Iran). Sodium azaide and sodium dodecyl sulfate (SDS) were purchased from Sigma Aldrich (USA) and Merck (Germany), respectively.

\subsection{Methods}

\subsubsection{Preparation of Emulsions}

SPC powder was rehydrated using deionized water at room temperature, and allowed to stand for $2 \mathrm{~h}$ to ensure complete hydration. This solution was adjusted to $\mathrm{pH} 8.0$ using phosphate buffer, and heated in a water bath (WB 14, Memmert, Germany) to $90^{\circ} \mathrm{C}$ for $30 \mathrm{~min}$ in order to denature proteins completely. Being denatured in proteins structure, result to opening their chain and a better contact between non polar and polar bonds which finally can improve emulsifier property and more stability in emulsions. Also denatured SPC is more viscose and can reduce droplet aggregation in emulsions which finally can reduce rate of creaming of them [14]. The denatured SPC solutions were cooled, and held at room temperature for $1 \mathrm{~h}$. On the other hand, MDX powder was dispersed in distilled water, and stirred overnight. Denatured SPC was mixed with MDX (in a ratio of 1:9) to form solutions with different solid concentrations (30, 35 and $40 \% \mathrm{w} / \mathrm{w})$ [15]. Then, lycopene $(5 \% \mathrm{w} / \mathrm{w})$ was dissolved in soy oil, and was mixed gradually $(10,15$ and $20 \% \mathrm{w} / \mathrm{w})$ with SPC + MDX solutions using a rotor-stator homogenizer (D 91126, Heidolf industries, Germany). To prepare coarse emulsions, $10000 \mathrm{rpm}$ was used for $5 \mathrm{~min}$. Furthermore, to prepare final emulsions, different rotation speeds (14000,
16000 and $18000 \mathrm{rpm}$ ) were used for $10 \mathrm{~min}$. Sodium azide $(0.01 \% \mathrm{w} / \mathrm{v})$ was added into emulsions to prevent microbial decay during storage. Emulsions were kept in glass tubes in water bath $\left(30^{\circ} \mathrm{C}\right)$ for further analysis.

\subsubsection{Microstructure and Droplet Size Determination of Emulsions}

The microstructure of emulsions was analyzed using a digital microscope (VIVA-BW 1008, Gaungdong, China) connected to a computer. Microscopic size measurement was carried out by taking photos of emulsions, and processing them by Image J (1.44P) software. Briefly, one droplet of emulsion was diluted in $100 \mathrm{~mL} 0.1 \% \mathrm{w} / \mathrm{v}$ SDS to prevent further droplet coalescence, and to reduce the droplet concentration down to about $0.01 \% \mathrm{v} / \mathrm{v}$, because the original emulsions were too concentrated for drop size analysis [16]. One droplet of this solution was placed on a slide glass, and photographed using microscope at 100x [17].

\subsubsection{Creaming}

Stability test was carried out during storage at $30^{\circ} \mathrm{C}$ according to the reference method [18, 19]. Emulsion samples were separated into a "cream" layer at the top and a transparent (or turbid) "serum" layer at the bottom after being transferred into glass tubes and stored at the appropriate temperature. The extent of creaming was characterized by the creaming index (CI) as described in Eq.1

$$
\mathrm{CI}=100 \times(\mathrm{Hs}+\mathrm{Hc}) / \mathrm{Ht}
$$

Hs: height of the serum layer inside the glass vessel Hc: height of the cream layer inside the glass vessel $\mathrm{Ht}$ : total height of emulsion

\subsubsection{Viscosity of Emulsions}

Approximately, $15 \mathrm{~mL}$ of each emulsion was taken, and its viscosity was measured using a viscometer (D 220, Brookfield, USA) at $30^{\circ} \mathrm{C}$.

\subsection{Experimental Design and Data Analysis}

Design Expert software version 6.0.2 (Minneapolis, MN) was used to design the experiment for stability optimization of emulsions. Face centered $(\alpha=1)$ central composite design with four central points was applied to determine the influence of three independent variables, SPC+MDX concentration (30-40w/w\%), lycopene content (10-20w/w\%) and homogenizer speed (14000-18000rpm) on stability of the emulsions. The un-coded (actual) and coded levels of the independent variables are illustrated in Table 1.

Table 1. Symbols, un-coded (actual) and coded levels of the independent variables

\begin{tabular}{|c|c|c|c|c|}
\hline \multirow{2}{*}{ Symbol } & \multirow{2}{*}{ Independent variables } & \multicolumn{3}{|c|}{ Coded levels } \\
\cline { 3 - 5 } & & -1 & 0 & 1 \\
\hline $\mathrm{X} 1$ & Homogenizer speed (rpm) & 14000 & 16000 & 18000 \\
\hline $\mathrm{X} 2$ & Lycopene content \% & 10 & 15 & 20 \\
\hline $\mathrm{X} 3$ & SPC+MD\% & 30 & 35 & 40 \\
\hline
\end{tabular}




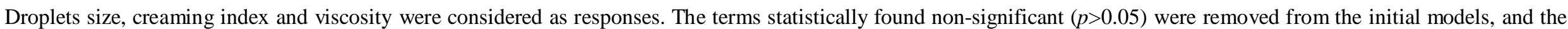

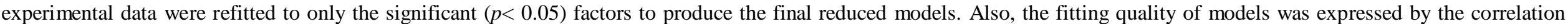
coefficients $\left(\mathrm{R}^{2}\right)$ and adjusted $\mathrm{R}^{2}$.

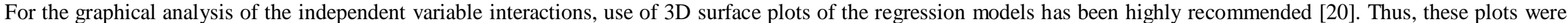
depicted from the fitted equations to explain the interactive effects of the independent variables against the response variables.

\section{Results and Discussions}

\subsection{Fitting the Models}

Measured responses (experimented and predicted values) which were considered as dependent variables, were given in Table 2.

Table 2. Predicted and experimental values of droplet size, viscosity and creaming index obtained from central composite experimental design of emulsions

\begin{tabular}{|c|c|c|c|c|c|c|c|c|c|}
\hline \multirow{2}{*}{$\begin{array}{c}\text { Experiment } \\
\text { number }\end{array}$} & & Independent variables & & & & Dependent variables & & & \\
\hline & Homogenizer speed (rpm) & Lycopene content $\% \mathrm{w} / \mathrm{w}$ & $\mathrm{SPC}+\mathrm{MD} \% \mathrm{w} / \mathrm{w}$ & Droplet size $(\mu \mathrm{m})^{2}$ & & Viscosity (cp) & & & Creaming index\% \\
\hline & $\mathrm{X} 1$ & $\mathrm{X} 2$ & X3 & Experimented & Predicted & Experimented & Predicted & Experimented & Predicted \\
\hline 1 & 16000 & 10 & 35 & 26.02 & 24.64 & 37.10 & 35.29 & 45.14 & 41.20 \\
\hline 2 & 16000 & 15 & 40 & 26.11 & 26.62 & 95.40 & 94.93 & 43.17 & 32.53 \\
\hline 3 & 14000 & 20 & 40 & 39.99 & 38.43 & 99.80 & 106.85 & 54.95 & 49.88 \\
\hline 4 & 16000 & 15 & 35 & 25.77 & 25.93 & 40.20 & 43.86 & 50.83 & 47.61 \\
\hline 5 & 14000 & 10 & 40 & 23.90 & 20.89 & 58.80 & 53.55 & 40.31 & 47.07 \\
\hline 6 & 18000 & 15 & 35 & 30.90 & 30.53 & 56.30 & 55.87 & 45.10 & 36.67 \\
\hline 7 & 16000 & 15 & 30 & 45.11 & 36.44 & 21.00 & 14.35 & 56.12 & 62.68 \\
\hline 8 & 14000 & 20 & 30 & 26.92 & 25.93 & 22.80 & 19.97 & 79.21 & 80.03 \\
\hline 9 & 16000 & 15 & 35 & 25.07 & 25.28 & 40.50 & 43.86 & 50.00 & 47.61 \\
\hline 10 & 18000 & 20 & 30 & 25.83 & 25.93 & 25.70 & 32.73 & 68.04 & 58.15 \\
\hline 11 & 16000 & 15 & 35 & 25.82 & 27.97 & 40.50 & 43.86 & 50.52 & 47.61 \\
\hline 12 & 18000 & 20 & 40 & 21.64 & 22.22 & 25.70 & 32.73 & 10.10 & 28.00 \\
\hline 13 & 14000 & 10 & 30 & 25.38 & 37.64 & 40.50 & 43.86 & 57.04 & 67.22 \\
\hline 14 & 18000 & 10 & 40 & 22.11 & 22.83 & 172.80 & 166.86 & 7.32 & 15.19 \\
\hline 15 & 14000 & 15 & 35 & 32.30 & 35.64 & 18.80 & 26.52 & 54.64 & 58.55 \\
\hline 16 & 16000 & 15 & 35 & 25.51 & 25.93 & 84.50 & 89.11 & 50.52 & 47.61 \\
\hline 17 & 18000 & 10 & 30 & 23.19 & 24.72 & 38.40 & 31.71 & 46.19 & 45.34 \\
\hline 18 & 16000 & 20 & 35 & 26.16 & 27.69 & 40.00 & 43.86 & 47.74 & 54.01 \\
\hline
\end{tabular}


Table 3. Analysis of variance for the regression coefficients of the fitted models for emulsions

\begin{tabular}{|c|c|c|c|c|c|c|c|c|c|}
\hline \multirow[b]{2}{*}{ Variables } & \multicolumn{3}{|c|}{ Droplet size } & \multicolumn{3}{|c|}{ Viscosity } & \multicolumn{3}{|c|}{ Creaming index } \\
\hline & $\begin{array}{l}\text { Regression } \\
\text { coefficient }\end{array}$ & $F$-value & $P$-value & $\begin{array}{l}\text { Regression } \\
\text { coefficient }\end{array}$ & $F$-value & $P$-value & $\begin{array}{l}\text { Regression } \\
\text { coefficient }\end{array}$ & $F$-value & $P$-value \\
\hline $\mathrm{X}_{0}$ & 25.93 & & & 43.86 & & & 47.61 & & \\
\hline \multicolumn{10}{|l|}{ Linear } \\
\hline $\mathrm{X}_{1}$ & -7.29 & 160.16 & $<0.0001$ & 12.08 & 29.17 & 0.0004 & -10.94 & 17.60 & 0.0009 \\
\hline $\mathrm{X}_{2}$ & 1.53 & 7.04 & 0.0226 & 17.80 & 63.32 & $<0.0001$ & 6.40 & 6.03 & 0.0277 \\
\hline $\mathrm{X}_{3}$ & -1.95 & 11.93 & 0.0060 & 40.29 & 324.43 & $<0.0001$ & -15.08 & 33.43 & $<0.0001$ \\
\hline \multicolumn{10}{|l|}{$2 \mathrm{~F} 1$} \\
\hline $\mathrm{X}_{1} \mathrm{X}_{2}$ & -01.54 & 5.71 & 0.0359 & 6.11 & 5.97 & 0.0371 & - & - & - \\
\hline $\mathrm{X}_{1} \mathrm{X}_{3}$ & 0.72 & 1.04 & 0.3376 & 11.81 & 22.31 & 0.0011 & - & - & - \\
\hline $\mathrm{X}_{2} \mathrm{X}_{3}$ & -0.29 & 0.17 & 0.6868 & 14.96 & 35.80 & 0.0002 & - & - & - \\
\hline \multicolumn{10}{|l|}{ Quadratic } \\
\hline $\mathrm{X}_{1}^{2}$ & 2.24 & 5.04 & 0.0463 & -0.069 & 0.0002 & 0.9883 & - & - & - \\
\hline $\mathrm{X}_{2}{ }^{2}$ & 0.23 & 0.036 & 0.8543 & 9.23 & 5.25 & 0.0476 & - & - & - \\
\hline $\mathrm{X}_{3}{ }^{2}$ & 2.64 & 6.95 & 0.0232 & 10.78 & 7.17 & 0.0253 & - & - & - \\
\hline $\mathrm{R}^{2}$ & 0.9571 & & & 0.9826 & & & 0.8030 & & \\
\hline Adj-R ${ }^{2}$ & 0.9089 & & & 0.9630 & & & 0.7608 & & \\
\hline
\end{tabular}

Most of the experimental values agreed well with the predicted ones obtained from RSM design and $\mathrm{R}^{2}$ was high enough for all the variables to conclude that these models could properly fit the experimental values.

Analysis of variances (ANONA) was used to evaluate the significance of the coefficients for each model (Table 3).

According to the ANOVA results, optimized variables showed a good fit to quadratic equations for droplet size and viscosity with correlation coefficients $\left(\mathrm{R}^{2}\right)$ of 0.9571 and 0.9826, respectively. After model simplification with backward stepwise solution, the $\mathrm{R}^{2}$ values for droplet size and viscosity decreased slightly to 0.9504 and 0.9826 , respectively. Creaming values were fitted properly with linear model and $\mathrm{R}^{2}$ was 0.8030 .

For any of the terms in the models, a large F-value and a small $p$-value indicate a more significant effect on the respective response variables [21]. Thus, the variable with the largest effect on the emulsion droplet size was the linear term of homogenizer speed, followed by the linear term of SPC+MDX concentration and lycopene content $(p<0.05)$. The quadratic terms of homogenizer speed and SPC+MDX concentration, as well as the interaction between homogenizer speed and lycopene content had significant influences on the droplet size of emulsions $(p<0.05)$.

For the creaming of emulsions, the largest effect was observed in case of linear term of SPC+MDX concentration, followed by those of homogenizer speed and lycopene content respectively $(p<0.05)$.

In case of viscosity, the highest influence was observed in case of linear term of SPC+MDX concentration, followed by those of lycopene content, interactive effect of SPC+MDX concentration and lycopene content, linear term of homogenizer speed and interactive effect of SPC+MDX concentration and homogenizer speed, respectively $(p<0.05)$. Similarly, viscosity was significantly affected by the quadratic terms of lycopene content and SPC+MDX concentration, as well as interactive effect of homogenizer speed and lycopene content $(p<0.05)$.

\subsection{D Surface Plots of the Emulsion Droplet Size}

The effect of independent variables on responses was visualized using 3D surface plots of the quadratic and linear models generated by two independent variables within the experimental range, while holding the other one constant at the central point.

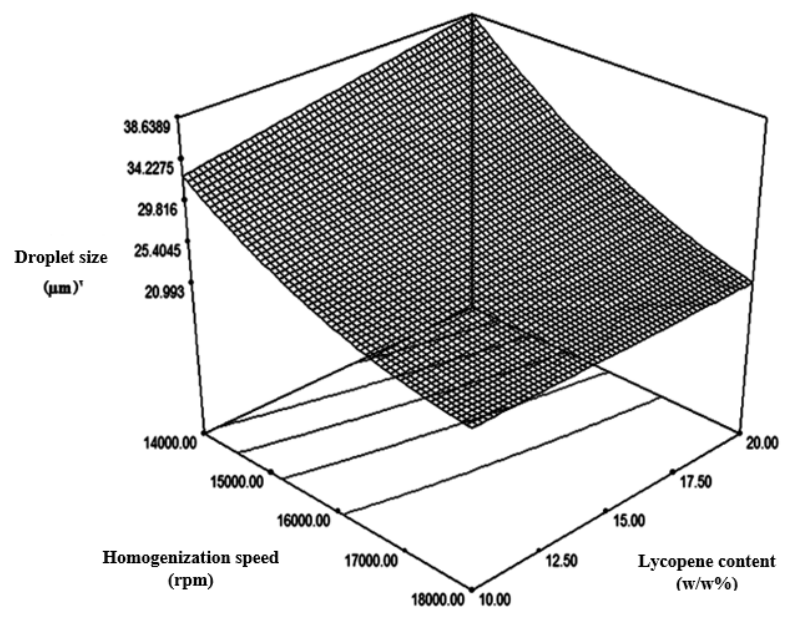

Figure 1. 3D surface plots of the emulsion droplet size as a function of lycopene content and homogenizer speed at a constant SPC+MD concentration (35\%) 
Results showed that an increase in homogenizer speed from 14000 to $18000 \mathrm{rpm}$ had a remarkable influence on droplet size of final emulsions and the droplet size significantly decreased with an increase in homogenizer speed $(p<0.05)$, mainly attributed to the influence of higher energy densities on the collision of droplets accompanied with enforcing them between the rotor and stator of the device. Our results agreed with those reported by Haznedar and Dortunc (2004), Sun and Gunasekaran (2009) and Gardouh etal., (2012) and Gupta et al (2015), [22, 23, 24, 25].

Also, the concentration of lycopene had significant effect on droplet size of emulsions, which slightly increased at higher concentrations $(p<0.05)$. It has been previously reported that higher concentrations of dispersed phase, hinder homogenization process, so higher energy density is needed to break down droplets and distribute them in the whole continuous phase (Haznedar and Dortunc, 2004; Mehnert and Mader, 2001 and Ghorab etal., 2004 and Mohammed et al., 2016), [22, 26, 27, 28].

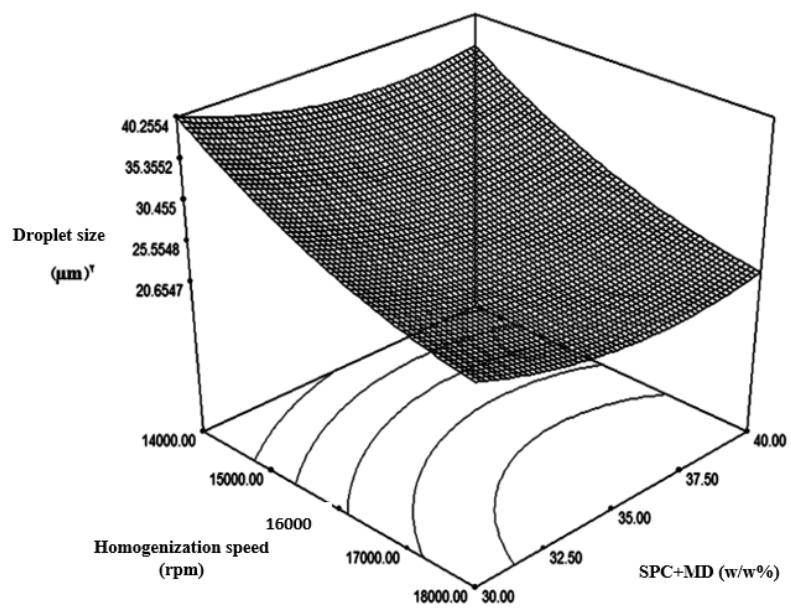

Figure 2. 3D surface plots of the emulsions droplet size as a function of the SPC+MD concentration and homogenizer speed at constant lycopene content $(15 \%)$

It was revealed that higher concentrations of SPC+MDX (from 30 to $40 \% \mathrm{w} / \mathrm{w}$ ) resulted in a significant decrease in droplet size $(p<0.05)$. In fact, higher viscosity of the continuous phase increases the impact rate between lycopene and the external phase, which results to a decrease in droplet size. Moreover, more concentrated emulations provide larger surface areas between emulsion droplets and the continuous phase, which allows the formation of smaller droplets. These findings were in agreement with those data obtained by Haznedar and Dortunc (2004), Mehnert and Mader, (2001) and Boom (2008) and Hosseini et al., 2015, [22, 26, 29, 30].

\subsection{D Surface Plots of the Emulsion Creaming Index}

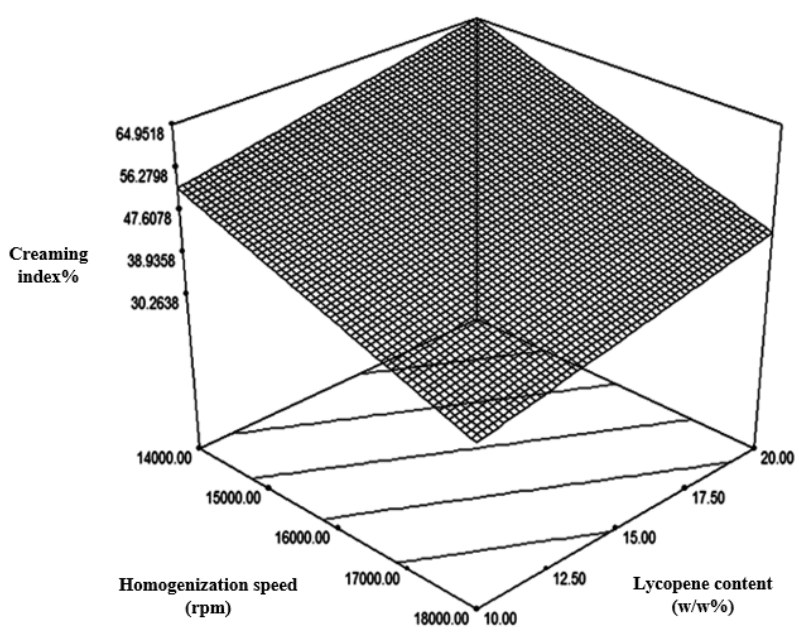

Figure 3. 3D surface plot of the creaming of the emulsions as a function of the lycopene content and homogenizer speed at constant SPC+MD concentration (35\%)

As shown in Figure 3, both homogenizer speed and lycopene content had a significant effect on creaming index $(p<0.05)$. Higher creaming index was observed at higher concentrations of lycopene, attributed to hindering of homogenization process, which resulted in larger droplets and accelerated phase separation due to gravitational forces.

On the other hand, homogenizer speed exhibited reverse effect on creaming index, which is attributed to larger and heavier droplets at lower homogenizer speeds [17]. These results were agreed with the findings of Haznedar and Dortunc (2004), Mehnert and Mader, (2001) and Ghorab etal. (2004), [22, 26, 27].

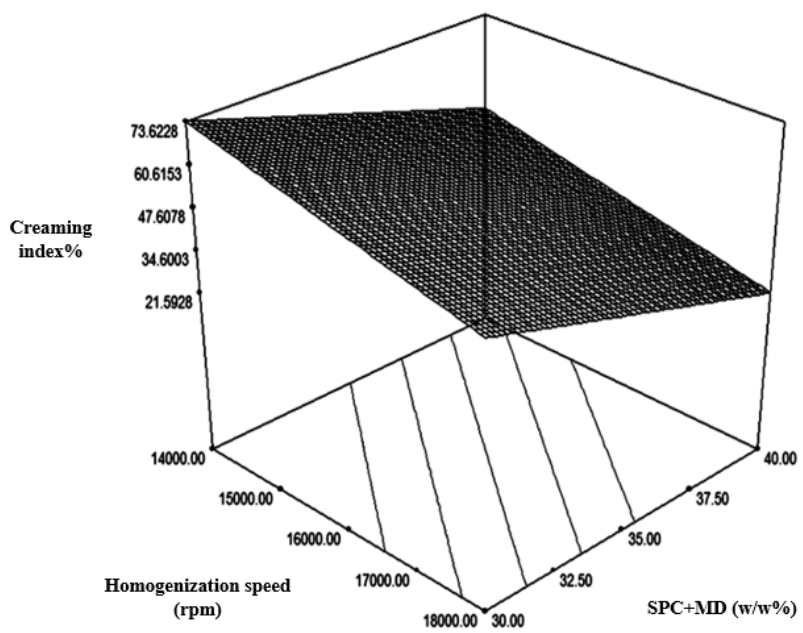

Figure 4. $3 \mathrm{D}$ surface plot of the creaming of the emulsions as a function of the SPC+MD concentration and homogenizer speed at constant lycopene content (15\%) 
Higher SPC+MDX concentration resulted in higher stability and lower creaming index. Using surfactants or (bio) polymers, which can adsorb onto the interface and rise electrostatic or steric repulsions between the droplets can postpone un-stabilization of emulsions. Also biopolymers can dissolve in continuous phase and influence the rheology of the continuous phase [28]. Our results were agreed with the findings of Dluzewska etal. (2006), Haznedar and Dortunc (2004) and Jafari etal. (2007b) and Hosseini et al., 2015. [31, 22, 11, 30]

\subsection{D Surface Plots of Emulsion Viscosity}

Effect of lycopene content and homogenizer speed on viscosity of emulsions was illustrated in Figure 5.

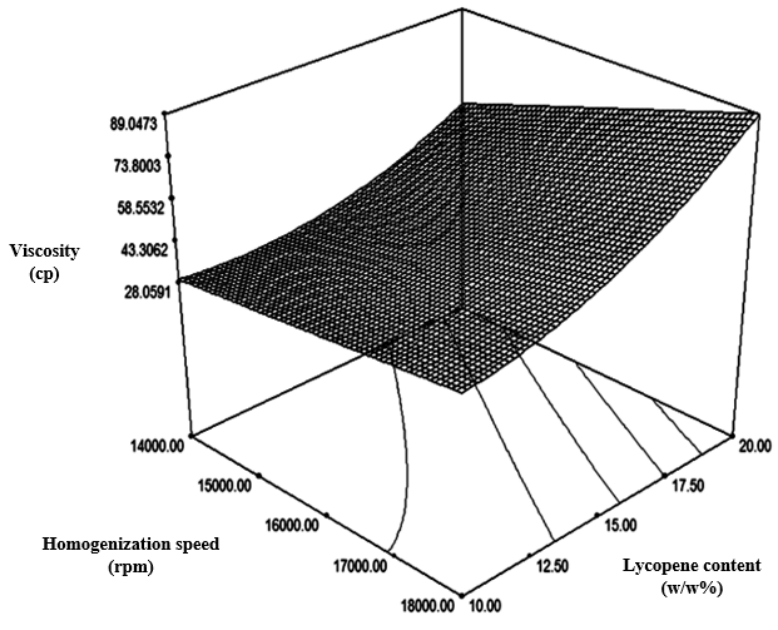

Figure 5. 3D surface plot of the viscosity of the emulsions as a function of the lycopene content and homogenizer speed at a constant SPC+MD concentration (35\%)

The viscosity was significantly affected by lycopene contents $(p<0.05)$. One of the most important factors, which can influence viscosity, is the disperse phase volume fraction, which is equal to the volume of emulsion droplets divided by the total volume of emulsion [6]. Disperse phase droplets can change hydrodynamic and colloidal interactions and consequently, the viscosity of system by increasing degree of disturbance of normal liquid flow [28, 30,32 , and 33]. Our results agreed with those of Daik et al. (2007), [34].

Additionally, viscosity was significantly affected by homogenizer speed $(p<0.05)$. A reduction in droplet size, resulted in an increase in the number of droplets in the system, and consequently, resulted in enhanced droplet-droplet interactions and an increased resistance to flow. These findings were agreed with those reported by Daik etal. (2007) and Hosseini et al., 2015. [33, 30]

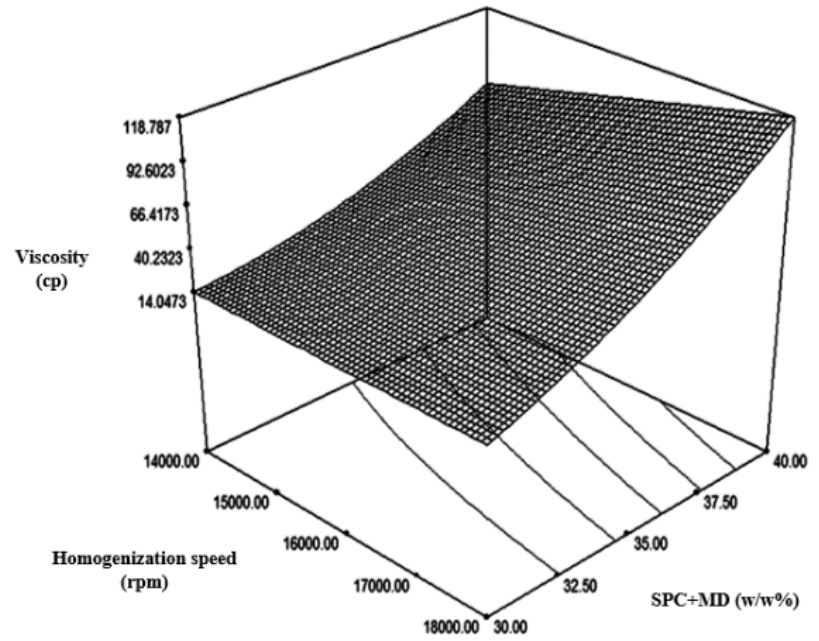

Figure 6. 3D surface plot of the viscosity of the emulsions as a function of the SPC+MD concentration and homogenizer speed at constant lycopene content (15\%)

Viscosity was more significantly affected by the concentration of solid material (SPC+MDX) as compared to homogenizer speed $(p<0.05)$. By increasing and adding more soluble materials in to emulsions, they bound with free water, and finally resulted to more viscose systems. This function, in emulations, can have significant effect on lowering creaming index and producing long-lasting systems.

\subsection{Optimization of Conditions for Preparing Lycopene Emulsions}

An emulsion can be more stable by decreasing droplet size and creaming index, so optimization was carried out by first superimposing the contour plots for the droplet size, creaming index and viscosity of the emulsion as functions of SPC+MDX concentration and lycopene content at a fixed homogenizer speed of 18000rpm (Figures 7a, 7b and 7c). Economically and technically, an emulsion with higher contents of lycopene and lower emulsifier concentration (SPC+MDX) is suggested. These assumptions, resulted in an optimum zone, in which, every point would represent a combination of SPC+MDX concentration and lycopene content that would give minimum values for the droplet size and creaming index, and maximum viscosity of the emulsions. Finally, from the principles mentioned above, the point at the lycopene content and emulsifier concentrations (SPC+MDX) of 20 and $36.95 \% \mathrm{w} / \mathrm{w}$, respectively, was chosen as the optimum point, along with the optimized homogenizer speed of 18000rpm. 


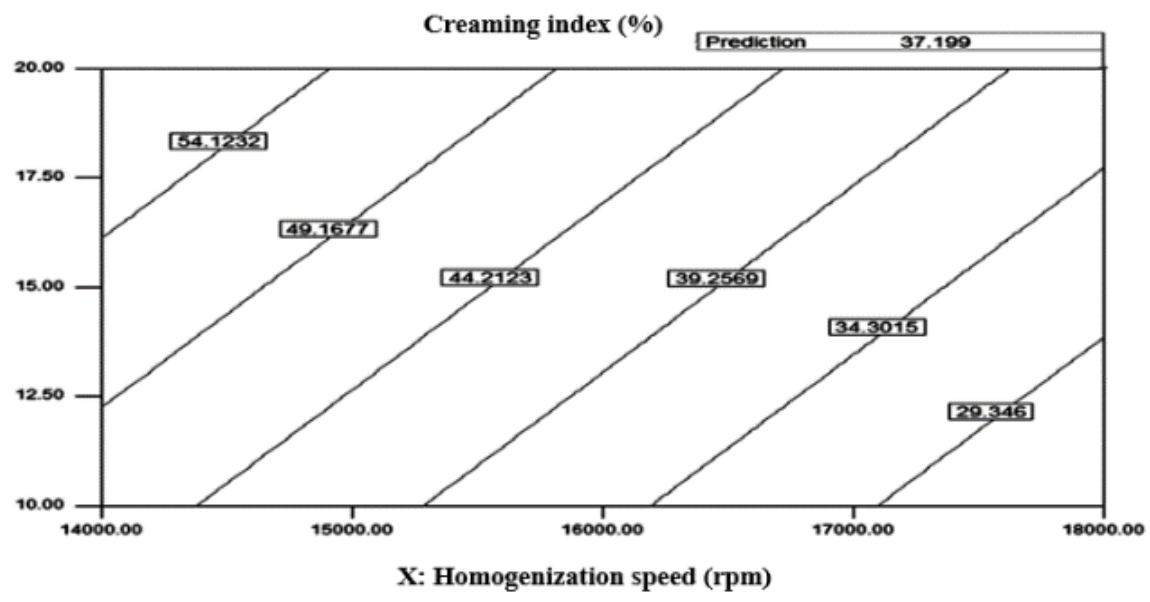

Y: Lycopene content (w/w\%)

(a)

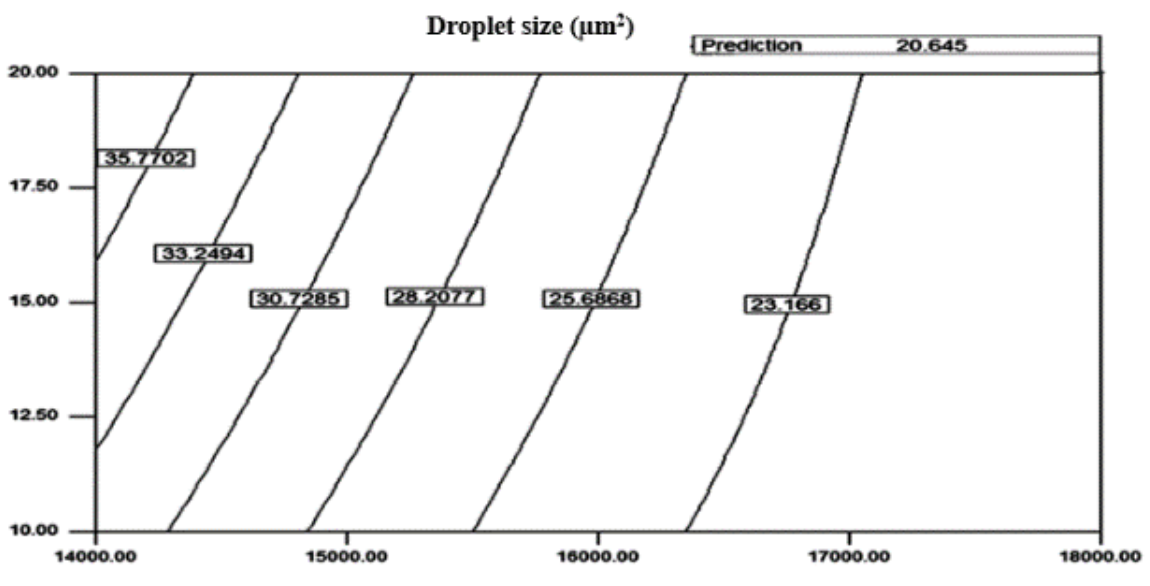

X: Homogenization speed (rpm)

Y: Lycopene content (w/w\%)

(b)

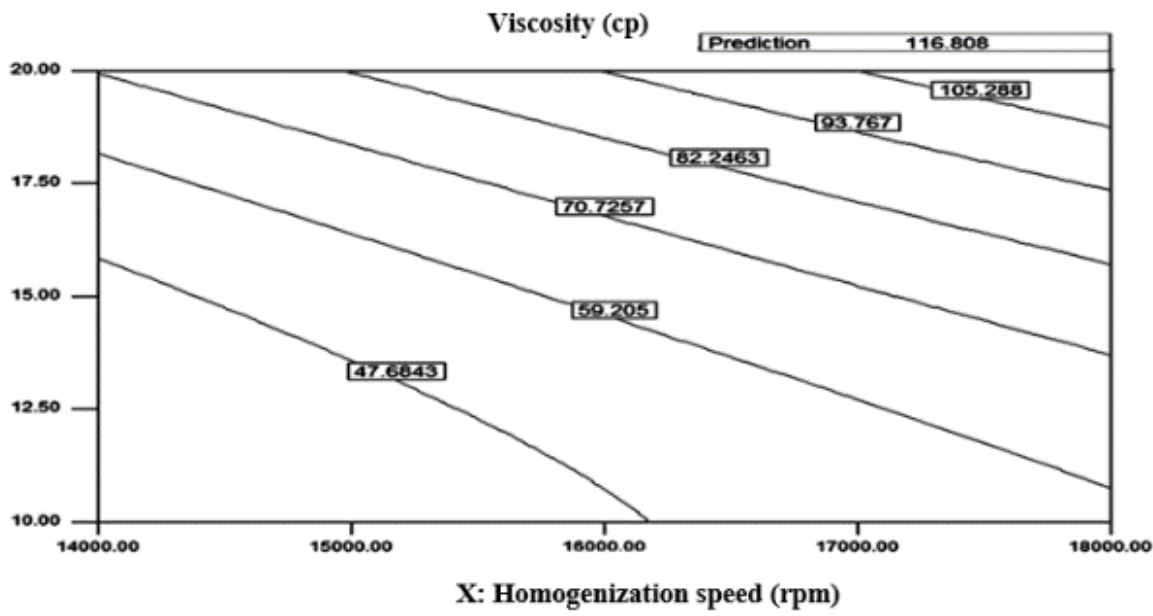

Y: Lycopene content (w/w\%)

(c)

Figure 7. Contour plots for the droplet size (a), creaming index (b) and viscosity(c) of the emulsion as a function of SPC+MD concentrations and lycopene content to find optimized point at a fixed homogenizer speed of 18000rpm 


\section{Conclusions}

Results showed that, according to RSM analysis and models, quadratic model was adequately fitted to optimize and predict the responses of droplet size and viscosity, but linear model was suggested for creaming index. The linear terms of homogenizer speed, SPC+MDX concentration and lycopene content, had the largest effects on the emulsion droplet size.

Linear terms of SPC+MDX concentration, homogenizer speed and lycopene content, significantly affected creaming index, but none of the quadratic terms and interactive effects significantly affected it.

Finally, emulsion viscosity was highly affected by linear terms of SPC+MDX concentration, lycopene content, as well as interactive effect of SPC+MDX concentration and lycopene content, linear term of homogenizer speed and interactive effect of SPC+MDX concentration and homogenizer speed, respectively. Additionally, quadratic terms of lycopene content and SPC+MDX concentration and interactive effect of homogenizer speed and lycopene content exhibited significant effect on viscosity.

The graphical optimization method was adapted to find the best emulsifying conditions, and it was predicted that the optimum conditions for preparing lycopene emulsions were: homogenizer speed of $18000 \mathrm{rpm}$; lycopene content of $20 \% \mathrm{w} / \mathrm{w}$, and SPC+MDX concentration of $36.95 \%$ $\mathrm{w} / \mathrm{w}$.

\section{REFERENCES}

[1] M .Farzi, Z. Emam-djomeh, and M.A. Mohammadifar. A comparative study on the emulsifying properties of various species of gum tragacanth, International Journal of Biological Macromolecules, Vol. 57, 76-82, 2013.

[2] D.J. McClements. Comments on viscosity enhancement and depletion flocculation by polysaccharide, Food Hydrocolloids, Vol. 14, 173-177, 2000.

[3] U. Klinkesorn, P. Sophanodora, P.Chinachoti, and D. McClements. Stability and rheology of corn oil-in-water emulsions containing maltodextrin, Food Research International, Vol. 37, 851-859, 2004.

[4] H. Mirhosseini, C.P. Tan, N.S.A. Hamid, S. Yusuf, and B.H. Churn. Characterization of the influence of main emulsion components on the physicochemical properties of orange beverage emulsion using response surface methodology, Food Hydrocolloids, Vol. 23, 271-280, 2009.

[5] R.D. Dombrowski, J.D. Litster, N.J. Wagner and Y. He Crystallization of alpha-lactose monohydrate in a drop-based microfluidic crystallizer, Chemical Engineering Science, Vol. 62, 4802-4810, 2007.

[6] D. J. McClements. Food emulsions: Principles, practice, and techniques (2cond Ed.), BocaRaton, FL: CRC Press, 2005.

[7] S. M. Jafari, P. Beheshti and E. Assadpoor. Rheological behavior and stability of D-limonene emulsions made by a novel hydrocolloid (Angum gum) compared with Arabic gum, Journal of Food Engineering, Vol. 109, 1-8, 2012.

[8] K. Matsumiya, W. Takahashi, T. Inoue and Y. Matsumura. Effects of bacteriostatic emulsifiers on stability of milk-based emulsions, Journal of Food Engineering, Vol. 96, 185-191, 2010.

[9] A. N. Ilia Anisa and A. H. Nour. Effect of Viscosity and Droplet Diameter on water-in-oil (w/o) Emulsions: An Experimental Study. World Academy of Science, Engineering and Technology, Vol. 38, 691-694, 2010.

[10] S. M. Jafari, Y. He and B. Bhandari, Effectiveness of encapsulating biopolymers to produce sub-micron emulsions by high energy emulsification techniques, Food Research International, Vol. 40, 862-873, 2007a.

[11] S. M. Jafari, Y. He and B. Bhandari. Production of sub-micron emulsions by ultrasound and microfluidization techniques, Journal of Food Engineering, Vol. 82, 478-488, 2007b.

[12] M. F. Anjum, I. Tasadduq and K. Al-Sultan, Response surface methodology: A neural network approach, European Journal of Operational Research, Vol. 101, 65-73, 1997.

[13] R. H. Myers and D. C. Montgomery. Response surface methodology: Process and product optimization using designed experiments. New York: John Wiley \& Sons, Inc.1995.

[14] G. Y. Gan, L. H. Cheng and A. M. Easa. Evaluation of microbial transglutaminase and ribose cross-linked soy protein isolate-based microcapsules containing fish oil, Journal of Innovative Food Science and Emerging Technologies, Vol. 9, 563-569, 2008.

[15] S. Tcholakova, N.D. Denkov and T. Danner. Role of Surfactant Type and Concentration for the Mean Drop Size during Emulsification in Turbulent Flow, Langmuir, Vol. 20, 7444-7458, 2004.

[16] F. Y. Ushikubo and R. L. Cunha. Stability mechanisms of liquid water-in-oil emulsions, Food Hydrocolloids, Vol. 34, 145-153, 2014.

[17] J. L. Li, Y. Q. Cheng, P. Wang, W. T. Zhao, L. J. Yin and M. Saiyo. A novel improvement in whey protein isolates emulsion stability: generation of an enzymatically cross-linked beet pectin layer using horseradish peroxidase, Food Hydrocolloids, Vol. 26, 448-455, 2012.

[18] F. Littoz and D. J. McClements. Bio-mimetic approach to improving emulsion stability: cross-linking adsorbed beet pectin layers using laccase, Food Hydrocolloids, Vol. 22, No. 7, 1203-1211, 2008.

[19] S. M. T. Gharibzahedi, S. M. Mousavi, M. Hamedi and M. Ghasemlou. Response surface modeling for optimization of formulation variables and physical stability assessment of walnut oil in-water beverage emulsions, Food Hydrocolloids, Vol. 26, 293-301, 2012.

[20] L. Quanhong and F. Caili. Application of response surface methodology for extraction optimization of germinant pumpkin seeds protein, Food Chemistry, Vol. 92, No. 4, 701-706, 2005.

[21] D. Bei, J. Marszalek and B. B. Youan. Formulation of 
Dacarbazine-loaded Cubosomes-Part II: Influence of Process Parameters, AAPS Pharm Sci. Tech., Vol. 10, No. 3, 1040-1047, 2009.

[22] S. Haznedar and B. Dortunc. Preparation and in vitro evaluation of Eudragit microspheres containing acetazolamide, International Journal of Pharmacy and Pharmaceutical Sciences, Vol. 269, No. 1, 131-140, 2004.

[23] C. Sun and S. Gunasekaran. Effects of protein concentration and oil phase volume fraction on the stability and rheology of menhaden oil-in-water emulsions stabilized by whey protein isolate with xanthan gum, Food Hydrocolloids, Vol. 23, 165-174, 2009.

[24] A. R. Gardouh, M. M. Ghorab and S. G. S. Abdel-Rahman. Effect of Viscosity, Method of Preparation and Homogenization Speed on Physical Characteristics of Solid Lipid Nanodroplets, ARPN Journal of Science and Technology, Vol. 2, No. 10, 966-1006, 2012.

[25] A. Gupta, H. Burak Eral, T. Alan Hatton and P.S. Doyle. Controlling and predicting droplet size of Nano emulsions: scaling relations with experimental validation, The Royal Society of Chemistry online journal, 2015.

[26] W. Mehnert and K. Mader. Solid lipid Nano droplets: production, characterization and applications, Advanced Drug Delivery Reviews, Vol. 47, 165-196, 2001.

[27] M. M. Ghorab, H. M. Abdel-salam and M. M. Abdel-Moaty. Solid lipid Nano droplets- effect of lipid matrix and surfactant on their physical characteristics, Bulletin of Pharmaceutical Sciences (Assiut University), Vol. 27, No. 1, 155-159, 2004.

[28] A. Mohammed, S. Ijeoma Okoye and J. Salisu. Effect of Dispersed Phase Viscosity on Stability of Emulsions
Produced by a Rotor Stator Homogenizer, Internationa Journal of Sciences: Basic and Applied Research, Vol. 25, No.2, 256-267. 2016

[29] R. M. Boom. Food material science, Emulsions: Principles and Preparation, New York: Springer, 2008.

[30] S.Hosseini, B.Ghiassi Tarzi, M. Gharachorloo, M. Ghavami and H. Bakhoda. Optimization on the Stability of Linseed Oil-in-Water Nano emulsions Generated by Ultrasonic Emulsification, Oriental Journal of Chemistry, Vol.31,No.2,1223-1230.2015.

Using Response Surface Methodology (RSM)

[31] C. Li, X. Fu, F. Luo and Q. Huang. Effects of maltose on stability and rheological properties of orange oil-in-water emulsion formed by OSA modified starch, Food Hydrocolloids, Vol. 32, 79-86, 2012.

[32] E. Dluzewska, A. Stobiecka and M. Maszewska. Effect of oil phase concentration on rheological properties and stability of beverage emulsions, ACTA Scientiarum Polonorum Technologia Alimentaria, Vol. 5, No. 2, 147-156, 2006.

[33] D. Quemada and C. Berli. Energy of interaction in colloids and its implications in rheological modeling, Journal of Colloid and Interface Science, Vol. 98, 51-85, 2002.

[34] D. J. Watson and M.R. Mackley. The rheology of aqueous emulsions prepared by direct emulsification and phase inversion from a high viscosity alkyd resin, Colloids and Surfaces A: Physicochemical and Engineering Aspects, Vol. 196, 121-134, 2002.

[35] R. Daik, S. Bidol and I. Abdullah. Effect of molecular weight on the droplet size and rheological properties of liquid natural rubber emulsion, Malaysian Polymer Journal (MPJ), Vol. 2, No. 1, 29-38, 2007. 